\title{
BULLYING HOMOFÓBICO NO CONTEXTO ESCOLAR EM PORTUGAL ${ }^{1}$
}

\author{
Raquel António 3 \\ Tiago Pinto ${ }^{2}$ \\ Catarina Pereira ${ }^{2}$ \\ Diana Farcas ${ }^{2}$ \\ Carla Moleiro ${ }^{2}$
}

Resumo: O presente estudo pretendeu explorar o fenómeno do bullying homofóbico em Portugal relativamente à sua prevalência, consequências e formas de agressão. Mediante um questionário online, distribuído pelos núcleos locais da Associação rede ex aequo e preenchido por 184 estudantes, verificou-se que, à semelhança de resultados internacionais, o recinto escolar é o local privilegiado para a ocorrência deste fenómeno. Os resultados indicam que prevalece a violência psicológica e a vitimização de rapazes; os comportamentos de agressão são desvalorizados; subsiste uma não intervenção nas situações presenciadas; existem consequências psicológicas significativas para as vítimas de bullying homofóbico, em comparação com as não-vítimas. Defende-se a importância de conceber programas de sensibilização, de criar medidas de protecção para as vítimas, e ainda de aprofundar a investigação desta temática.

Palavras-chave: bullying, homofobia, orientação sexual, escola

Homophobic Bullying in School Context in Portugal (Abstract): The present study intended to explore the phenomenon of homophobic bullying in Portugal, concerning its prevalence, consequences and ways of aggression. Through an online questionnaire, distributed to the local core network of the ex aequo association, and completed by 184 students, it was found that the school grounds is a main location for the occurrence of this phenomenon, just as the international studies revealed.

\footnotetext{
${ }^{1}$ Nota: O presente trabalho apresenta alguns dados preliminares do trabalho desenvolvido pela primeira autora, no âmbito da sua dissertação de Mestrado, sob a supervisão da última autora. $\mathrm{O}$ estudo foi realizado em colaboração com a rede ex aequo e apoiado pela Comissão para a Cidadania e Igualdade de Género (CIG).

2 ISCTE-IUL, CIS-IUL

3 raquelmantonio@gmail.com
} 
The results indicate that psychological violence and victimization of boys are more prevalent; aggressive behaviors are devalued; the witnessed situations lack intervention; there are significant psychological consequences for the victims of homophobic bullying, compared to non-victims. It is argued for the importance of developing awareness programs, creating protective measures for victims, and further investigation of this issue.

Keywords: bullying, homophobia, sexual orientation, school

\section{Introdução}

\section{Bullying}

Nos últimos anos, a temática de violência nas escolas tem vindo a receber uma maior atenção na área da investigação e dos media. O bullying é uma forma específica de violência nas escolas, sendo definida por Olweus (1993), como "um(a) aluno(a) estar a ser provocado/vitimado quando ele ou ela está exposto, repetidamente e ao longo do tempo, a acções negativas da parte de uma ou mais pessoas" (p. 9). As acções negativas podem ser verbais (e.g. chamar nomes), físicas (e.g. bater), sexuais (e.g. tocar em partes do corpo do outro deixando-o desconfortável), ou sociais (e.g. excluir), contribuindo para a distinção entre o bullying "directo" (que envolve um ataque manifesto a uma vítima) e o bullying "indirecto" (que está relacionado com o isolamento social e exclusão de um grupo). Destaca-se ainda o cyberbullying, que envolve o uso de tecnologias de informação e comunicação (e-mail, telemóvel, pager, etc.) como forma de agressão. Green (2008) afirma que estes dois tipos de bullying podem ocorrer no intervalo, na hora de almoço, antes ou depois da escola, tendo sempre uma ou mais vítimas e um/a ou mais agressores (bullies).

A maioria dos estudos indica que o bullying é mais frequente entre estudantes dos 6 aos 15 anos, onde a percentagem de vitimização se encontra entre 58 e 77 valores (e.g. Poteat \& Espelage, 2005). Hoover e Oliver, em 1996, afirmaram que $80 \%$ dos/as estudantes já foi vítima de bullying na sua escola, pelo menos uma vez, nos Estados Unidos da América. Estudos feitos em Inglaterra referem que em $68 \%$ das escolas existem alunos/as que já foram alvos de alguma forma de bullying (O'Higgins - Norman, 2008).

Em Portugal, investigações com amostras representativas, em 1998, verificou-se que $42.5 \%$ dos/as alunos/as entre os 11 e os 16 anos de idade relataram nunca se terem envolvido em comportamentos de bullying, $10.2 \%$ afirmaram serem agressores/as, $21.4 \%$ referiram serem vítimas e $25.9 \%$ eram simultaneamente vítimas e agressores/as (Carvalhosa, Lima \& Matos, 
2001). Por sua vez em 2004, constatou-se que $41.3 \%$ dos/as alunos/as nunca estiveram envolvidos em situações de bullying, 9.4\% foram agressores/as, $22.1 \%$ foram vítimas e $27.2 \%$ foram vítimas e agressores/as (Carvalhosa, 2007). Registou-se um maior envolvimento dos rapazes nos comportamentos de bullying e um declínio destes comportamentos no final da adolescência para ambos os sexos (Formosinho, Taborda \& Fonseca, 2008). As agressões físicas apresentam-se como a forma mais comum de bullying nas escolas portuguesas do $1^{\circ}$ ciclo, ainda que a partir do $2^{\circ}$ ciclo se registe uma maior prevalência das agressões verbais (Carvalhosa, Moleiro \& Sales, 2009) e do cyberbullying (Almeida et al, 2008).

As investigações têm revelado que tanto os bullies como as vítimas de bullying podem sofrer repercussões significativas ao nível do bem-estar emocional, da saúde e da aprendizagem (Green, 2008). Por norma, as vítimas apresentam baixos níveis de auto-estima, sociabilidade e felicidade, pior desempenho escolar, auto-imagem e auto-avaliação negativas, elevados níveis de ansiedade, e uma maior tendência para a depressão e desintegração social (e.g. Carvalhosa, 2009; Craig, 1998; Rigby \& Slee, 1993; Solberg \& Olweus, 2003). Green (2008) realça que as vítimas de bullying têm uma maior tendência para manifestar dores de estômago, dores de cabeça e, em casos mais graves, apresentam uma maior tendência para a auto-mutilação e tentativas de suicídio. Por seu turno, os/as bullies apresentam uma maior prevalência de comportamentos anti-sociais e agressivos fora do contexto escolar, um maior consumo de substâncias, como álcool e drogas, elevados níveis de ansiedade, impulsividade, auto-imagem positiva e necessidade de dominar os outros, queixas físicas e psicológicas, e problemas escolares (Carvalhosa, 2009; Carvalhosa, Lima \& Matos, 2001; Olweus, 1993; Rigby \& Slee, 1993; Solberg \& Olweus, 2003).

\section{Bullying Homofóbico}

Apesar da investigação sobre bullying e vitimização ter sofrido um aumento significativo nos últimos anos, verifica-se que a sua relação com outras áreas, como a homofobia, tem sido menos estudada (Poteat \& Espelage, 2005). A homofobia corresponde a qualquer forma de discriminação feita com base numa orientação sexual não-heterossexual (Oliveira, Pereira, Costa \& Nogueira, 2010), envolvendo assim crenças, atitudes, estereótipos e comportamentos negativos (e.g. irritar, ameaçar, importunar) para com indivíduos homossexuais e bissexuais (Wright, Adams \& Bernat, 1999). Assim, o bullying homofóbico pode ser caracterizado por comportamentos associados ao bullying no geral (e.g. agressões físicas, verbais, sexuais), mas revestidos de teor homofóbico. É exemplo o conteúdo verbal utilizado em situações de homofobia e situações de bullying (utilização da orientação sexual como forma insulto; Poteat \& Espelage, 2005). 
É evidente a relação entre bullying e homofobia, considerando que as experiências negativas reportadas por estudantes LGBT (Lésbicas, Gays, Bissexuais e Transgénero) englobam, sobremaneira, o bullying exercido de forma continuada no tempo (Takács, 2006). Segundo alguns autores (e.g. Adams et al., 2004), o bullying homofóbico pode tornar-se mais grave relativamente ao bullying em geral por ser menos visível e menos credibilizado do que as outras formas de bullying, inclusivamente pelos/as próprios/as professores/as.

É de salientar que o comportamento de bullying homofóbico pode ser expresso em relação quer a pessoas heterossexuais, quer LGBT, ou seja, também existem estudantes heterossexuais que podem ser vítimas de homofobia, não pela sua orientação sexual, mas porque são percebidos/as como sendo diferentes das expectativas tradicionais do papel de género masculino ou feminino (Poteat \& Espelage, 2005).

Neste sentido, a investigação existente sugere que a homofobia e o bullying homofóbico mostram ser uma consequência negativa dos estereótipos de papel de género (O'Higgins-Norman, 2008). Para o autor, o bullying homofóbico pode ser dividido em dois tipos: (a) o bullying subjacente ao carácter hetero-normativo do ambiente escolar, relacionado com as expectativas de papel de género independentemente da orientação sexual da vítima, nomeadamente ao nível do policiamento dos comportamentos considerados representativos dos géneros feminino e masculino; e (b) o bullying que tem por base comportamentos discriminatórios e persecutórios contra pessoas LGBT.

A prevalência do bullying homofóbico, apesar das dificuldades inerentes à sua avaliação, parece ser bastante elevada, sendo que cerca de $92 \%$ dos indivíduos LGBT já foram vítimas de comentários homofóbicos, $84 \%$ afirma ter sido ofendido/a verbalmente, $83 \%$ sofrer insultos, ameaças, violência física e sexual (Poteat \& Espelage, 2005). Segundo O'Higgins-Norman (2008), 45\% dos gays e 20\% das lésbicas, nos Estados Unidos da América, já experienciou agressões físicas e verbais por parte de outros/as estudantes devido à sua orientação sexual. Por sua vez, 53\% já ouviu comentários homofóbicos por parte dos/as funcionários/as da escola. No Reino Unido, um estudo desenvolvido pela associação Stonewall com a participação de mais de 1100 adolescentes, demonstrou que 65\% dos/as estudantes LGBT com menos de 18 anos já foram vítimas de bullying homofóbico directo e mais de $95 \%$ foram expostos/as a agressões verbais de teor homofóbico (Stonewall, 2007).

Em Portugal, apesar da escassez de resultados relacionados com o bullying homofóbico, é possível revelar alguns indicadores. Tendo por base os resultados obtidos pela Associação rede ex aequo (associação de jovens lésbicas, gays, bissexuais, transgéneros e simpatizantes em Portugal), através do Observatório de Educação LGBT, realizado em 2008 em território nacio- 
nal, a maior parte das queixas de situações de homofobia em ambiente escolar regista-se entre o final da adolescência e o início da idade adulta e em grandes centros urbanos, nomeadamente Lisboa, com $38 \%$ das queixas e o Porto, com $12 \%$ (rede ex aequo, 2008).

A baixa auto-estima, isolamento, dificuldades de concentração, fobia à escola e tentativas de suicídio são alguns exemplos das consequências do bullying homofóbico (e. g. Adams et al., 2004; Berlan et al., 2010; Harry, 1989; Hershberger \& D’Augelli, 1995; Ritter \& Terndrup, 2002; Russell, 2003). A longo prazo, Adams et al. (2004) apontam como consequências os sentimentos de culpa, depressão e ansiedade, bem como receio de estabelecer relações interpessoais e timidez. Deste modo, os efeitos deste tipo de bullying englobam, sobretudo, a perda de confiança, a diminuição da auto-estima e do desempenho escolar, e o aumento do abandono da escola (O’Higgins-Norman, 2008). Adicionalmente, os/as jovens LGBT, vítimas de bullying homofóbico, revelam um elevado risco de tentativas de suicídio e elevados níveis de depressão e suicídio (Robertson \& Monsen, 2001).

Assim, o presente estudo tem por objectivo efectuar uma caracterização do fenómeno do bullying homofóbico em Portugal, ao nível das suas formas de agressão, prevalência e consequências, comparando-se posteriormente estes dados com os resultados observados a nível internacional.

\section{Método}

\section{Participantes}

Participaram neste estudo 184 estudantes de Portugal continental, com idades compreendidas entre 12 e 20 anos $(\mathrm{M}=17$; $\mathrm{DP}=1.68)$. Do total de participantes, 54\% ( $\mathrm{n}=99)$ eram do sexo feminino e a maioria frequentava o $12^{\circ}$ ano $(50.5 \%)$. A amostra contou com a participação de jovens de todos os distritos de Portugal continental, sendo que 33\% estudava em Lisboa. Relativamente à sua orientação sexual, $34 \%(n=63)$ dos/as participantes identificaram-se como homossexuais, $27 \%(n=49)$ como bissexuais, $25 \%(n=46)$ como heterossexuais, e os/as restantes optaram por não responder à questão ou declararam ter dúvidas relativamente à sua orientação sexual.

\section{Instrumentos}

A recolha de dados foi feita através do preenchimento de um questionário online, composto por várias secções. Inicialmente, após a apresentação de uma definição de bullying e de bullying homofóbico, a primeira parte do questionário, composta por 11 questões, destinava-se à recolha de dados biográficos. A segunda parte do questionário tinha como objectivo avaliar o 
bullying homofóbico e as suas consequências físicas e psicológicas. Para tal recorremos a um conjunto de questões de instrumentos internacionais, a saber, o Homophobic Content Agent Target Scale (HCAT), desenvolvido por Poteat e Espelage (2005); o Speakout Survey (Stonewall, 2007); e o Clinical Outcomes in Routine Evaluation (CORE-OM; Barkham et al., 1998).

A versão adaptada da escala HCAT (Poteat \& Espelage, 2005) utilizada inclui questões relativas à vitimização e agressão verbal, como "Na última semana, quantas vezes as seguintes pessoas te chamaram estes nomes [e.g. maricas, gay, lésbica, etc.]" ou "Na última semana, quantas vezes chamaste estes nomes [e.g. maricas, gay, lésbica, etc.]", especificando-se posteriormente o alvo (e.g. "alguém que não conhecias", "alguém de quem não gostas", "alguém que julgas ser homossexual", etc.). Encontra-se assim duas sub-escalas: de alvo/vítima e de agente/bully, com 5 itens cada. As respostas aos itens eram dadas numa escala de Likert de cinco pontos, em que 1 correspondia a "Nunca" e 5 a "Muito Frequentemente". Os autores da escala encontraram boas qualidades psicométricas da mesma, através de índices de precisão ( $\alpha=.85$, cada sub-escala), análise factorial ( 2 factores, $41 \%$ e $16 \%$ da variância), e correlação com diversas outras medidas, mostrando boa validade convergente e divergente.

A partir do Speakout Survey (Stonewall, 2007), foram extraídos os itens referentes a diferentes formas de agressão (e.g. "Agressão verbal", "Agressão física", "Por posts na internet ou blogs"), consequências para o agressor (e.g. "O que aconteceu ao agressor?"), outras características relativas à situação de bullying (como o local, intervenientes, etc) e algumas das suas consequências escolares e relacionais. As hipóteses de resposta variavam consoante o conteúdo do item, apresentando-se, em alguns casos, sob a forma de uma escala de Likert de cinco pontos. Esta escala foi já utilizada no Reino Unido para dois estudos ao nível nacional, com o objectivo de caracterizar a prevalência, características e consequências do bullying homofóbico nas escolas Britânicas, tendo revelado não só adequabilidade na investigação, como na aplicabilidade a jovens.

Do CORE-OM (Barkham et al., 1998), foi utilizada a versão reduzida e dirigida a adolescentes (YP-CORE), para a avaliar as consequências psicológicas do bullying. O CORE-OM é composto por 4 dimensões: bem-estar subjectivo, queixas/sintomas, funcionamento social e pessoal, e comportamentos de risco para com o próprio e/ou outros. É uma escala amplamente utilizada em investigação e em clínica/psicoterapia, com excelentes qualidades psicométricas. A versão reduzida para adolescentes tem apenas 10 itens, traduzindo o nível de bem-estar psicológico global. As respostas são dadas numa escala de Likert de cinco pontos, em que 1 correspondia a "Nunca" e 5 a "Muito Frequentemente". Estas medidas foram já traduzidas para português, tendo dados preliminares para população clínica e não clínica (Sales et 
al., 2008). Para a avaliar as consequências do bullying a nível de problemas de comportamento para além das emocionais de carácter mais internalizante, foram acrescentados 6 itens de comportamentos externalizantes e de consumos de substâncias (que não fazem parte da versão reduzida).

\section{Procedimento}

O questionário foi elaborado através da plataforma Google docs, tendo sido gerado um link de acesso que foi enviado por e-mail para os núcleos locais da Associação rede ex aequo, através dos quais foi encaminhado a jovens de idades compreendidas entre os 12 e os 20 anos. Foi-lhes explicado que o questionário se destinava a recolher opiniões dos/as estudantes acerca de alguns aspectos da sua vida escolar e que a sua colaboração seria fundamental para a compreensão das relações humanas na escola, assegurando-se a confidencialidade e anonimato das respostas e o carácter voluntário da participação (American Psychological Association, 2002; Ordem dos Psicólogos Portugueses, 2011). O consentimento informado foi, assim, obtido junto dos participantes e, apesar de estes serem menores de idade em muitos casos, o consentimento dos pais ou representantes legais não foi procurado. Essa escolha foi feita por ter sido a associação rede ex aequo, à qual pertenciam de forma autónoma, uma parceira na investigação e por não ser requerido que os jovens tivessem revelado a sua orientação sexual aos seus representantes legais (constituindo-se uma situação de excepção à obtenção do seu consentimento).

O questionário esteve online durante dois meses, tendo os dados sido posteriormente analisados através do programa SPSS.

\section{Resultados}

Num primeiro momento, realizou-se uma análise dos resultados de forma a obter-se uma caracterização geral e descritiva do bullying homofóbico na amostra. Neste sentido, verificou-se que $42 \%$ dos/as participantes afirmaram já ter sido intimidados/as, insultados/as ou agredidos/as na escola por ser homossexual ou bissexual, ou por alguém que os/as via como sendo homossexual ou bissexual. Para além disso, a maioria dos/as estudantes inquiridos/as declararam já ter visto outras pessoas serem vítimas de bullying homofóbico (67\%), sendo que $40 \%$ das vítimas foram alunos/as que eram ou podiam ser vistos/as como homossexuais ou bissexuais. $\mathrm{O}$ local mais comum onde os/as participantes afirmam ter ocorrido estas situações foi dentro do recinto escolar (28\%), ou quer dentro quer fora da escola (67\%).

Pode-se constatar igualmente que $57 \%$ das situações foram presenciadas por mais pessoas para além do/a inquirido/a, sendo que $32 \%$ das pessoas 
não fizeram nada, $22 \%$ riram-se da situação, e apenas $17 \%$ pediram ao/à agressor/a para parar. Nos casos em que a situação não foi vista por mais ninguém para além dos/as participantes, apenas $20 \%$ contou a amigos/as da escola o que presenciou, registando-se percentagens baixas de relatos das situações a adultos, nomeadamente a professores/as (7.8\%) e aos progenitores $(1.6 \%)$. Em $80 \%$ das situações de bullying homofóbico, os/as inquiridos/as revelaram que não aconteceu nada ao/à agressor/a, sendo que em apenas $14 \%$ das situações o/a agressor/a foi repreendido/a.

Posteriormente, foram realizadas análises estatísticas com o intuito de categorizar os diferentes tipos de bullying e melhor definir o fenómeno a nível das suas consequências, e diferenças de sexo e orientação sexual.

Deste modo, foram agrupadas as diferentes formas de bullying homofóbico presentes nos itens referentes ao Speakout Survey (Stonewall, 2007), através de uma Análise por Componentes Principais (ACP), recorrendo ao método de rotação Varimax $\left(\mathrm{KMO}=.851\right.$; Bartlet $\chi^{2}(55)=1082.787$, $\mathrm{p}<0.001$ ) e usando o critério de Kaiser para extracção de factores (valores próprios iguais ou superiores a 1). A solução final revelou um total de três factores que explicam $71.84 \%$ da variância total (ver Tabela 1). O primeiro factor obtido, Violência Psicológica, refere-se às agressões verbais, exclusão e isolamento, bem como aos mexericos e boatos, tendo apresentado uma boa consistência interna $(\alpha=.90)$. O segundo factor, Violência Física e Sexual, remete para um tipo de agressão que envolve agressões e ameaças à integridade física e agressões sexuais, apresentando uma consistência interna elevada $(\alpha=.78)$. Por último, o terceiro factor, Cyberbullying, está relacionado com as agressões perpetradas através da Internet (e.g. publicação de posts) ou do telemóvel, tendo apresentado uma consistência interna também elevada $(\alpha=.83)$. A Violência Psicológica registou uma maior ocorrência média $(M=2.12)$, em detrimento do Cyberbullying $(M=1.29)$, e da Violência Física e Sexual $(M=1.15)$, explicando $27.64 \%$ da variação.

Uma vez que a forma de violência psicológica foi aquela que registou uma maior frequência de ocorrência, tornou-se imprescindível analisar a escala de agressão verbal HCAT (Poteat \& Espelage, 2005), que permite avaliar até que ponto os/as alunos/as praticam ou sofrem agressões verbais de teor homofóbico. A escala, dividida entre agressão e vitimização, revelou elevados valores de consistência interna (agressores, $\alpha=.82$; vítimas, $\alpha=.86$ ), tendo-se verificado um maior frequência média na sub-escala de vítimas $(M=1.64)$ do que na de agressores $(M=1.40)$. 
Tabela 1: Análise por Componentes Principais (ACP) referente às Formas de Bullying Homofóbico

\begin{tabular}{|c|c|c|c|c|c|c|c|c|c|}
\hline \multirow{3}{*}{$\begin{array}{l}\text { Se foste alvo de bull- } \\
\text { ying homofóbico, com } \\
\text { que frequência foste } \\
\text { sujeito(a) a: }\end{array}$} & \multicolumn{9}{|c|}{ Factores } \\
\hline & \multicolumn{3}{|c|}{$\begin{array}{l}\text { Violência } \\
\text { Psicológica }\end{array}$} & \multicolumn{3}{|c|}{$\begin{array}{c}\text { Violência Física e } \\
\text { Sexual }\end{array}$} & \multicolumn{3}{|c|}{ Cyberbullying } \\
\hline & Loading & $M$ & $\overline{D P P}$ & Loading & 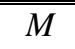 & $\overline{D D P}$ & $\overline{\text { Loading }}$ & 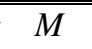 & $\overline{D P P}$ \\
\hline Agressão verbal & .886 & 2.28 & 1.39 & & & & & & \\
\hline Mexericos ou boatos & .854 & 2.37 & 1.49 & & & & & & \\
\hline Olhares intimidantes & .798 & 2.03 & 1.30 & & & & & & \\
\hline Ignorado/a ou isolado/a & .751 & 1.82 & 1.30 & & & & & & \\
\hline $\begin{array}{l}\text { Ameaça grave à tua } \\
\text { integridade }\end{array}$ & & & & .864 & 1.07 & .46 & & & \\
\hline Agressão física & & & & .725 & 1.21 & .59 & & & \\
\hline Agressão sexual & & & & .624 & 1.07 & .29 & & & \\
\hline $\begin{array}{l}\text { Estragar ou roubar } \\
\text { coisas }\end{array}$ & & & & .704 & 1.26 & .71 & & & \\
\hline $\begin{array}{l}\text { Instant messag- } \\
\text { ing/chat/e-mail }\end{array}$ & & & & & & & .869 & 1.32 & .81 \\
\hline $\begin{array}{l}\text { Posts na Internet ou } \\
\text { blogs }\end{array}$ & & & & & & & .821 & 1.26 & .68 \\
\hline Telemóvel & & & & & & & .788 & 1.29 & .78 \\
\hline $\begin{array}{l}\text { Variância explicada } \\
(\%)\end{array}$ & & 7.638 & & 22. & 627 & & & .569 & \\
\hline $\begin{array}{l}\text { Consistência interna } \\
(\alpha)\end{array}$ & & 0.90 & & 0. & 78 & & & .83 & \\
\hline$M$ & & 2.12 & & 1. & 15 & & & .29 & \\
\hline$D P$ & & .201 & & .4 & 06 & & & 658 & \\
\hline
\end{tabular}

Com o objectivo de verificar o impacto das consequências psicológicas e físicas decorrentes da vitimização por bullying homofóbico, foram 
realizados testes $t$ para comparação de médias, de modo a comparar as consequências entre as vítimas de bullying homofóbico e as não-vítimas. A distinção entre os dois grupos foi feita com base na pergunta "Já alguma vez foste intimidado(a), insultado(a), ou agredido(a) na escola por seres homossexual ou bissexual, ou por alguém que pensava que que eras homossexual ou bissexual?". Assim, verificaram-se diferenças estatisticamente significativas entre vítimas e não-vítimas em quase todas as consequências avaliadas, conforme a Tabela 2. Deste modo, constatou-se que as vítimas de bullying homofóbico, quando comparadas com as não-vítimas, apresentam maiores níveis médios de consequências psicológicas (i.e. o bem-estar psicológico avaliado com os itens do YP-CORE foi inferior para as vítimas de bullying homofóbico). As vítimas reportaram, por exemplo, sentir-se significativamente mais tristes, sozinhas, irritadas e, inclusivamente, ter mais vontade de se magoarem a si próprias. As consequências ao nível da segurança na escola $(\mathrm{t}(1,182)=-4.68, \mathrm{p}<.01)$, do sentido de comunidade escolar $(\mathrm{t}(1,182)=-4.29$, $\mathrm{p}<.01$ ), e no próprio desempenho escolar ("Tiveste dificuldade em concentrar-te na escola"; $\mathrm{t}(1,182)=4.33, \mathrm{p}<.01)$ também foram mais elevadas para as vítimas. Finalmente, alguns problemas de comportamento foram também significativamente superiores nas vítimas de bullying (como "Agiste sem pensar", $\mathrm{t}(1,182)=2.10, \mathrm{p}<.05$; e "Tiveste muitas discussões", $\mathrm{t}(1$, $182)=2.68, \mathrm{p}<.05)$. Apenas não se verificaram diferenças significativas relativas aos indicadores de consumos de substâncias (tabaco, álcool e drogas).

Neste estudo procurou-se ainda averiguar as diferenças relativamente à vitimização por bullying homofóbico, nomeadamente em função do sexo e da orientação sexual. Mediante os testes realizados, foi possível verificar que os rapazes foram aqueles que apresentaram maiores níveis percentuais de vitimização (56.4\%), comparativamente com as raparigas $(43.6 \%)$, níveis esses que revelaram uma diferença estatisticamente significativa $\left(\chi^{2}=5.68\right.$, $p<.05)$.

Por sua vez, aqueles que se identificaram como sendo homossexuais apresentaram maiores níveis percentuais de vitimização (48.7\%), comparativamente com os/as alunos/as que se identificam como bissexuais (34.6\%) e heterossexuais $(5.1 \%)$, sendo estas diferenças também estatisticamente significativas $\left(\chi^{2}=33.72, p<.01\right)$. 
Tabela 2: Diferenças de Médias das Consequências para Vítimas e Não-Vítimas de Bullying Homofóbico

\begin{tabular}{|c|c|c|c|c|c|}
\hline \multirow[b]{2}{*}{ Consequências } & \multirow[b]{2}{*}{$t$} & \multicolumn{2}{|c|}{ Vítimas } & \multicolumn{2}{|c|}{ Não-Vítimas } \\
\hline & & $M$ & $D P$ & $M$ & $D P$ \\
\hline Sentiste-te irritado/a ou nervoso/a & $3.324 * *$ & 3.51 & 1.192 & 2.90 & 1.279 \\
\hline $\begin{array}{l}\text { Não tiveste vontade de falar com } \\
\text { ninguém }\end{array}$ & $6.278 * *$ & 3.46 & 1.203 & 2.34 & 1.194 \\
\hline $\begin{array}{l}\text { Sentiste que eras capaz de lidar } \\
\text { com as coisas que correm mal }\end{array}$ & -1.729 & 2.96 & 1.145 & 3.25 & 1.130 \\
\hline Pensaste em magoar-te & $4.732 * *$ & 2.26 & 1.490 & 1.42 & 0.883 \\
\hline $\begin{array}{l}\text { Sentiste coragem para pedir ajuda } \\
\text { a alguém }\end{array}$ & $-2.490 *$ & 1.97 & 1.139 & 2.47 & 1.468 \\
\hline $\begin{array}{l}\text { Os teus pensamentos e sentimentos } \\
\text { fizeram-te sentir mal ou sofrer }\end{array}$ & $5.313 * *$ & 3.46 & 1.306 & 2.41 & 1.351 \\
\hline $\begin{array}{l}\text { Sentiste que os teus problemas } \\
\text { eram demais para ti }\end{array}$ & $4.750 * *$ & 3.22 & 1.402 & 2.28 & 1.256 \\
\hline $\begin{array}{l}\text { Sentiste dificuldade em adormecer } \\
\text { ou ficar a dormir (a noite toda) }\end{array}$ & $3.866^{* *}$ & 3.12 & 1.405 & 2.33 & 1.329 \\
\hline Sentiste-te triste & $5.599 * *$ & 3.74 & 1.167 & 2.73 & 1.254 \\
\hline Fizeste todas as coisas que querias & $-2.169 *$ & 2.40 & 1.049 & 2.76 & 1.192 \\
\hline Sentiste-te sozinho/a & $6.284 * *$ & 3.36 & 1.367 & 2.17 & 1.191 \\
\hline Agiste sem pensar & $2.098^{*}$ & 2.65 & 1.347 & 2.26 & 1.165 \\
\hline $\begin{array}{l}\text { Tiveste um bom comportamento } \\
\text { em casa e na escola }\end{array}$ & -.637 & 3.74 & 1.050 & 3.85 & 1.153 \\
\hline Tiveste muitas discussões & $2.684^{*}$ & 2.54 & 1.077 & 2.08 & 1.172 \\
\hline Fumaste tabaco & 1.032 & 2.26 & 1.724 & 2.00 & 1.621 \\
\hline Bebeste álcool & 1.054 & 1.83 & 1.304 & 1.65 & 1.042 \\
\hline Usaste outras substâncias/drogas & 1.517 & 1.40 & 1.036 & 1.21 & .658 \\
\hline $\begin{array}{l}\text { Tiveste dificuldade em concentrar- } \\
\text {-te na escola }\end{array}$ & $4.334 * *$ & 3.09 & 1.240 & 2.32 & 1.151 \\
\hline Sentes-te seguro/a na tua escola & $-4.680 * *$ & 3.38 & 1.072 & 4.13 & 1.070 \\
\hline Sentes-te parte da tua escola & $-4.288 * *$ & 3.05 & 1.172 & 3.80 & 1.174 \\
\hline
\end{tabular}

$g l=182 \quad * p<0.05 \quad * * p<0.01$ 


\section{Discussão}

O presente estudo teve como objectivo efectuar uma caracterização do fenómeno do bullying homofóbico em Portugal, ao nível das suas formas de agressão, prevalência e consequências. Os resultados obtidos permitiram constatar que a maioria dos/as jovens estudantes já presenciou situações de bullying homofóbico contra alunos/as que são ou que se pensa que possam ser homossexuais ou bissexuais, sendo que a maioria das situações ocorreram dentro do recinto escolar. À semelhança dos resultados encontrados noutros estudos (e.g. D'Augelli et al., 2002; O'Higgins-Norman, 2008), os resultados obtidos sugerem que os rapazes portugueses são mais frequentemente vítimas de bullying homofóbico, comparativamente com as raparigas.

Ao nível da intervenção em situações de bullying homofóbico, verificou-se que apesar das situações de vitimização serem presenciadas por terceiros, na maioria dos casos ninguém intervém e apenas em poucas situações é pedido ao/à agressor/a para parar com o seu comportamento. Regista-se ainda uma elevada percentagem de comportamentos que incentivam o comportamento do/a agressor/a e desvalorizam a agressão (e.g. risos). É de realçar ainda que os resultados indicam que, na esmagadora maioria das situações, os/as agressores/as parecem não ter consequências face ao seu comportamento, ou seja, são raras as ocasiões em que estes/as sofrem qualquer tipo de sanção. Este contexto é também reportado em outros países (e.g. no Reino Unido, Stonewall, 2007). Neste sentido, verifica-se a falta de sensibilização para as questões do bullying e homofobia entre os/as mais novos/as, permanecendo, muito provavelmente, crenças que legitimam atitudes e comportamentos agressivos para com os indivíduos que não correspondam aos papéis de género normativos ou que manifestem uma orientação sexual não heterossexual.

Relativamente aos tipos de bullying homofóbico, os resultados obtidos demonstram maiores níveis de violência psicológica do que de violência física, o que vai de encontro ao demonstrado em estudos semelhantes (O’Higgins-Norman, 2008; Poteat \& Espelage, 2005).

Do mesmo modo, verificou-se que as consequências psicológicas decorrentes do bullying homofóbico são notoriamente superiores para as vítimas do que para aqueles/as que não foram vítimas, destacando-se o isolamento, tristeza e solidão, tal como outros autores haviam evidenciado (e. g. Adams et al., 2004; Russell, 2003). É ainda de referir que as vítimas de bullying homofóbico afirmam igualmente sentir-se menos seguras na escola, sentindo-se menos integradas no seio da comunidade escolar, sendo este um resultado que vai de encontro a outros estudos (e.g. Berlan et al., 2010). Com efeito, importa ponderar a necessidade de se criarem redes formais ou infor- 
mais de suporte social para as vítimas de bullying homofóbico, que possam diminuir a ocorrência destas situações e atenuar as suas consequências ao nível psicológico.

Contrariamente aos resultados de outros estudos (e.g. D'Augelli et al., 2002; Ritter \& Terndrup, 2002), não se registaram diferenças ao nível das consequências relativas a consumos de substâncias entre vítimas e não-vítimas, o que poderá reflectir o facto de estes serem comportamentos que têm padrões de consumos diferentes dos anglo-saxónicos entre os/as jovens portugueses, e que, para mais, tiveram respostas médias bastante baixas e pouca variabilidade na nossa amostra.

A realização deste estudo permitiu constatar que a discriminação com base na orientação sexual ou no carácter hetero-normativo do ambiente escolar está presente em escolas portuguesas, assumindo características análogas às encontradas em estudos realizados noutros países (e.g. nos EUA por Kosciw, Diaz \& Graytak, 2008; no Reino Unido por Stonewall, 2007). À semelhança do que tem vindo a ser desenvolvido nesses países, em Portugal foi recentemente lançado um projecto escolar que visa a sensibilização contra o bullying homofóbico, o Projecto Inclusão, desenvolvido pela Associação rede ex aequo. É ainda exemplo o projecto recente "Tod@s somos precis@s" ("It takes all kinds"), iniciativa do Instituto Dinamarquês dos Direitos Humanos, que conta com a colaboração de 10 países Europeus, entre os quais Portugal, promovido pela ILGA Portugal (2012). Contudo, mantém-se a necessidade de se criarem mais programas de sensibilização, bem como medidas de protecção e redes de apoio formais e informais contra a homofobia e o bullying homofóbico, em ambiente escolar. De facto, a investigação tem mostrado que medidas escolares (como a implementação de regras inclusivas anti-bullying, formação dos/as profissionais nas escolas, inclusão de temáticas LGBT nos curricula, ou a criação de núcleos de alunos/as LGBT) são eficazes a diminuir o número de agressões verbais e assédio de alunos/as LGBT, a diminuir o absentismo, a aumentar o nível percebido de segurança na escola e sentimento de pertença, e até mesmo aumentar o sucesso escolar (Kosciw, Diaz \& Graytak, 2008).

O presente estudo apresenta algumas limitações metodológicas. A recolha de dados constitui a maior limitação, dado que foi efectuada através da maior associação de apoio a jovens LGBT e simpatizantes do país, o que tornou a amostra não representativa da população juvenil em Portugal (uma sobre-representação de jovens homossexuais e bissexuais). Mais ainda, foi utilizada uma amostragem em cadeia, assegurando de forma mais estruturada a participação dos/as jovens. Esses/as jovens tinham ainda algum tipo de suporte social informal através desta associação. A metodologia de recolha de dados, através de questionário online, também apresenta algumas limitações. Muito embora se revele eficaz na recolha de maiores amostras, princi- 
palmente entre os/as mais jovens, não permite garantir alguns aspectos metodológicos e éticos relevantes (e.g. participação de menores de idade sem consentimento parental; garantia de resposta única por participante; impossibilidade de controlar as condições de resposta).

Uma vez que a existência de suporte social e/ou parental pode moderar as consequências do bullying homofóbico, estudos futuros poderão debruçar-se sobre esta questão, bem como recorrer a uma amostra mais ampla e representativa de jovens portugueses e explorar as diferenças entre as características do bullying homofóbico e do bullying no geral. Não obstante, pensamos que o presente trabalho contribui para uma melhor caracterização deste fenómeno em Portugal, que se reveste de uma crescente importância social.

\section{Referências}

Adams, N., Cox, T., \& Dunstan, L. (2004). 'I Am the Hate that Dare Not Speak its Name': Dealing with homophobia in secondary schools. Educational Psychology in Practice, 20, 3.

Almeida, A., Correia, I., Esteves, C., Gomes, S., Garcia, D., \& Marinho, S. (2008). Espaços virtuais para maus tratos reais: as práticas de cyberbullying numa amostra de adolescentes portugueses. In R. Astor, E. Debardieux \& C. Neto (Eds.), 4th World Conference on Violence in School and Public Policies (pp. 134). Lisboa: Edições FMH.

American Psychological Association (2002). Ethical principles of psychologists and code of conduct. Washington, DC: American Psychological Association.

Associação rede ex aequo - Associação de jovens Lésbicas, Gays, Bissexuais, Transgéneros e simpatizantes (2008). Relatório sobre Homofobia e Transfobia: Observatório de Educação LGBT. Lisboa: Relatório não publicado.

Barkham, M., Evans, C., Margison, F., McGrath, G., Mellor-Clark, J., Milne, D., \& Connell, J. (1998). The rationale for developing and implementing core outcome batteries for routine use in service settings and psychotherapy outcome research. Journal of Mental Health, 7, 35-47.

Berlan, E., Corliss, H., Field, A., Goodman, E., \& Austin, S. (2010). Sexual Orientation and Bullying Among Adolescents in the Growing Up Today Study. Journal of Adolescent Health, 46, 366-371.

Carvalhosa, S. F. (2009). Prevention of bullying in schools: An ecological model. International Journal of Developmental and Educational Psychology, 1(4), 129-134.

Carvalhosa, S., Lima, L., \& Matos, M. (2001). Bullying - A provocação/vitimação entre pares no contexto escolar português. Análise Psicológica, 4, 523-537.

Carvalhosa, S., Moleiro, C., \& Sales, C. (2009). A situação do bullying nas escolas portuguesas. Interacções, 13, 125-146. 
Craig, W. M. (1998). The relationship among bullying, victimization, depression, anxiety, and aggression in elementary school children. Personality and Individual Differences, 24, 123-130.

D’Augelli, A. R., Pilkington, N. W., \& Hershberger, S. L. (2002). Incidence and Mental Health Impact of Sexual Orientation Victimization of Lesbian, Gay, and Bisexual Youths in High School. School Psychology Quarterly, 17(2), 148-167.

Espelage, D. L., \& Swearer, S. M. (2008). Addressing Research Gaps in the Intersection Between Homophobia and Bullying. School Psychology Review, 37(2), 155-159.

Espelage, D. L., Aragon, S. R., \& Birkett, M. (2008). Homophobic Teasing, psychological Outcomes, and Sexual Orientation Among High School Students: What Influence Do Parents and Schools Have? School Psychology Review, 37(2), 202-216.

Formosinho, M., Taborda, M. C., \& Fonseca, A. (2008). Bullying in adolescence: Data from Portuguese school. In R. Astor, E. Debardieux \& C. Neto (Eds.), 4th World Conference on Violence in School and Public Policies (pp. 33). Lisboa: Edições FMH.

Green, V. A. (2008). Bullying. In N. J. Salkind (Ed.) Encyclopedia of Educational Psychology (pp. 119-124). Sage Publications: USA.

Harry, J. (1989). Sexual identity issues. In ADAMHA, Report of the Secretary's Task Force on Youth Suicide (DHHS Publication No. ADM 89-1622; Vol. 2, pp. 131-142). Washington, DC: U.S. Government Printing Office.

Hershberger, S. L., \& D'Augelli, A. R. (1995). The Impact of Victimization on the Mental Health and Suicidality of Lesbian, Gay, and Bisexal Youths. Developmental Psychology, 31(1), 65-74.

ILGA Portugal (2012).Tod@s somos precis@s/It takes all kinds. Projecto internacional retirado de http://www.ittakesallkinds.eu/info/pt/ a 30 de Janeiro de 2012.

Kosciw, G.K., Diaz, E.M., \& Graytak, E.A. (2008). The 2007 National School Climate Survey: The experiences of Lesbian, Gay, Bisexual and Transgender Youth in our Nation's schools. New York: Gay, Lesbian and Straight Education Network.

O'Higgins -Norman (2008). Equality in the provision of social, personal and health education in the Republic of Ireland: the case of homophobic bullying? Pastoral Care in Education, 26, 2, 69-81.

Oliveira, J., Pereira, M., Costa, C., \& Nogueira, C. (2010). Pessoas LGBT - Identidades e discriminação. In C. Nogueira, J.M. Oliveira, M. Almeida, C. Costa, L. Rodrigues e M. Pereira, Estudo sobre a discriminação em função da orientação sexual e da identidade de género (pp. 149-209). Lisboa: Comissão para a Cidadania e a Igualdade de Género.

Ordem dos Psicólogos Portugueses (2011). Código Deontológico. Regulamento n. ${ }^{\circ}$ 258/2011, Diário da República, 258, 17931-17936.

Poteat, V. P., \& Espelage, D. L. (2005). Exploring the relation between bullying and homophobic verbal content: The Homophobic Content Agent Target (HCAT) Scale. Violence and Victims, 20, 513-528. 
Rigby, K., \& Slee, P. T. (1993). Dimensions of interpersonal relating among Australian school children and their implications for psychological well-being. Journal of Social Psychology, 133, 33-42.

Ritter, K. Y., \& Terndrup, A. I. (2002). Handbook of Affirmative Psychotherapy with Lesbians and Gay Men. New York: The Guildford Press.

Robertson, L., \& Monsen, J. J. (2001). Issues in the development of a homosexual identity: Practice implications for educational psychologists. In J. J. Monsen (Ed.), Gay and lesbian identities: Working with young people, their families and school. Educational and Child Psychology (Special Issue), 18, 13-32.

Russell, S. T. (2003). Sexual Minority Youth and Suicide Risk. American Behavioral Scientist, 46(9), 1241-1257.

Solberg, M., \& Olweus, D. (2003). Prevalence estimation of school bullying with the Olweus bully/victim questionnaire. Aggressive Behavior, 29, 239-268.

Sales, C., Moleiro, C., Gonçalves, S., Silva, I., Duarte, J., \& Evans, C. (2008). Translation of the CORE-OM into Portuguese and initial data on its use in Portugal. Oral paper presentation at the 39th SPR International Meeting, Barcelona, 18-21 June 2008.

Stonewall (2007). The School Report: The experiences of young gay people in Britain's schools. UK: Autor.

Takács, J. (2006). Social exclusion of young lesbian, gay, bisexual and transgender (LGBT) people in Europe. ILGA-Europe and IGLYO.

Wright, L. W., Adams, H. E., \& Bernat, J. (1999). Development and Validation of the Homophobia Scale. Journal of Psychopathology and Behavioral Assessment, 21, 337-347. 